\title{
CRISIS Y PERSPECTIVAS TEÓRICAS EN SUDAMÉRICA
}

Patricio Quiroga*

RESUMEN: En un contexto de crisis de la economía, el debate sobre América Latina comienza a reaparecer en el horizonte, con una dimensión holística, es decir, con el regreso del pensamiento crítico, con un énfasis especial en la teoría del sistema-mundo.

yose

ABSTRACT: In the current economic crisis, the debate about Latin American resurfaces with a holistic view, namely a return to critical thinking, with a particular focus on the worldsystems theory.

PALABRAS ClAVE: Sudamérica, crisis, intelectualidad, teoría crítica, teoría de la dependencia, sistema-mundo.

KEY WORDS: South America, crisis, intellgentsia, critical theory, dependency theory, Worldsystems theory.

RECEPCIÓN: 12 de agosto de 2011.

APROBACIÓN: 17 de abril de 2012.

* Universidad de Valparaíso, Chile. 


\title{
CRISIS Y PERSPECTIVAS TEÓRICAS EN SUDAMÉRICA
}

\author{
El capitalismo-de-los-bordes que ha caracterizado \\ a la región se inscribe en una trama mayor, \\ delimitada por la expansión de un sistema-mundo \\ y una economía-mundo en el que la hegemonía \\ mundial, desde el siglo XVII, se ha trasladado de \\ Holanda a Inglaterra y de allí a los Estados \\ Unidos. Ahora bien,estas transiciones \\ se han caracterizado por la irrupción de \\ períodos convulsos, uno de los cuales estamos \\ viviendo por la evidente pérdida de la potencia \\ norteamericana. De alli la necesidad de \\ explorar respuestas globales a un desafio en \\ el cual la actual crisis mundial pudiera ser \\ reflejo del inicio de una nueva transición, reto que \\ demanda a la intelectualidad crítica de los países \\ periféricos reflexionar sobre sus propios \\ materiales de trabajo intelectual.
}

(Recomposición capitalista, teoría derrotada, renacimientos teóricos, cambio universal)

\section{La teoría derrotada}

\section{La recomposición capitalista (1974)} se sustentó en tres variables arrolladoras, a saber: la derrota política del movimiento obrero y popular, las políticas de shock económico y la reversión cultural que permitió el despliegue del pensamiento único, tendencia reforzada por la denominada "guerra silenciosa", los Acuerdos de Santa Fe I, II, III, IV, y el Consenso de Washington. ${ }^{1}$

${ }^{1} \mathrm{Al}$ respecto, sobre la guerra silenciosa, recientemente ha sido publicado "Silent weapons for quiet wars" un extenso documento editado por influyentes círculos conservadores norteamericanos; fue dado a conocer por primera vez en mayo de 1979. El documento entrega consideraciones para obtener un público dócil por medios legales. Se trata de despolitizar a la ciudadanía por medio de una serie de procedimientos (generación de ignorancia, confusión, individualismo, desmotivación). El texto precede a Santa Fe I, en http:// www.syti. net/ Es silent weapons.html. Sobre Santa Fe, “Acuerdo de Santa Fe I", en Revista Liberación, 1988, Buenos Aires; Santa Fe II, III, IV, en http://www.google.cl/search ¿client=fire fox-arevl=org El Consenso de Washington 
La ola de golpes de Estado en Sudamérica no solamente reconfiguró el poder político (Bolivia, 1972), si no que puso en el epicentro la alianza civil-militar (Uruguay, 1973), inició la reconversión capitalista en la región (Chile, 1973), e inauguró la práctica de la detencióndesaparición a escala (Argentina, 1976); la ofensiva también se hizo sentir en el plano teórico, puesto que la teoría crítica no estuvo en condiciones de afrontar la arremetida. En ese sentido, debe tomarse en cuenta que la teoría social es un producto que se trabaja en la larga duración, con el objeto de develar racionalmente la sociedad y que cualquier corte en su evolución demande readecuaciones, situación a las que se sumaron la desarticulación de la sociedad civil y del partido, considerado en ese entonces como un intelectual colectivo (según la fórmula de Gramsci), el cierre de las unidades académicas dedicadas al cultivo de las ciencias sociales y las humanidades, y la detención y desaparición de numerosos intelectuales. En fin, el estudio y representación de la sociedad se dificultó. ${ }^{2}$

fue formulado originalmente por J. Williamson en 1989 (What Washington Means by Policy Reform). Al cabo de un año se transformó en un decálogo de diez puntos para ser aplicado en las economías de los países pertenecientes a América Latina.

${ }^{2}$ Por ejemplo, para caracterizar el nuevo Estado surgieron diferentes visiones acompañadas de sus respectivas tipologizaciones; a saber: Fascismo (L. Corvalán), Fascismo dependiente (O. Caputo), Fascismo militar (E. Hackethal), Estado de la seguridad nacional (L. Maira), Estado burocrático militar (F. O’ Donnell), Estado de contrainsurgencia (R. Mauro), Estrategocracia (J. Tapia), Estado "gorila" (M. Enríquez), Estado de excepción, (M. Carranza), Nuevo autoritarismo (D. Collier) y Estado militar (A. Rouquie). En fin, la discusión al respecto no se resolvió y, al igual que otros temas, quedó sin respuesta. Tendencia captada certeramente por S. Mainwaring, para quien, "lo mejor de la ciencia social en Sudamérica ha cambiado significativamente desde fines de la década de los sesentas y comienzos del setentas. Los aportes más sólidos se han alejado del tema de la dependencia y del análisis de clase inspirados en la tradición marxista”, en Desarrollo económico, 1984, vol. 24, núm. 95. Luego, vendría la nueva representación de la sociedad con El Otro Sendero de H. de Soto (Perú), La Revolución Silenciosa de J. Lavín (Chile) o la conversión neoliberal de Paz Estenssoro (Bolivia). Pero, no fue todo, porque los vacíos teóricos de aquellos años explican la falta de respuesta al cambio histórico que se experimentaba, a la inserción de América Latina en la economíamundo, a las tipologías transicionales, a la amplitud de las alianzas políticas, a la revalorización de la democracia. Cuestiones graves en un mundo que se disolvía y que tendrían incidencia en las futuras transiciones y las dificultades de ésta para vadear el neoliberalismo, aunque también es necesario tomar en cuenta, ¿hasta dónde los actores políticos y sociales, y los intelectuales podían, desde la teoría derrotada, enfrentar los nuevos desafíos? 
Ahora bien, nuestra hipótesis es que ese impacto está en vías de reconstrucción y que en Sudamérica la teoría crítica comienza a experimentar un nuevo ciclo de florecimiento intelectual. Al respecto, pensamos que en la región, cada cuarenta años (aproximadamente), se experimenta un auge crítico-cultural que tiene que ver con el agotamiento de las generaciones precedentes, que van dejando el paso a las nuevas que irrumpen con nuevos temas, metodologías, teorías y epistemologías. Así lo demuestran, entre otros, el reclamo de Bolívar contenido en la Carta de Jamaica (1815), la Iniciativa de la América propuesta por F. Bilbao (1856), el clamor de Martí en Nuestra América (1891), los 7 Ensayos de interpretación de la realidad peruana de Maríategui (1928), la producción dependentista-marxista, y la de la teología de la liberación en los sesenta y parte de los setenta del siglo pasado.

Como señalábamos anteriormente, en el contexto de la crisis de los setenta, los partidarios del cambio social también fueron derrotados teóricamente. Pero no fue todo; muy pronto los derrotados habrían de sufrir los efectos de una nueva avalancha; en menos de un lustro, desde los grandes centros de pensamiento se puso en interdicción la teoría crítica, quedando la reflexión teórica encuadrada por la sospecha a que se sometieron los ahora denominados metarrelatos, ofensiva que puso en entredicho los paradigmas prevalentes al poner una nota de incertidumbre sobre los mapas cognitivos, quebrantándose la confianza en la eficacia de los registros de acercamiento al estudio de la sociedad. ${ }^{3}$ Esta tendencia reafirmada, entre otros fenómenos, por la derechización de occidente (1979) y el desplome del socialismo de Estado (1989), tuvo un formi-

${ }^{3}$ Las razones de esta crisis fueron numerosas y difíciles de identificar. Por un lado, están los aspectos teóricos; por otro, los políticos. Entre los primeros deben consignarse la crisis de los paradigmas forjados o renovados en la posguerra y su profundización por los cambios histórico-universales que condujeron a la polémica modernidad/postmodernidad, al abandono de teorías sociales, a la triple crisis (marxismo, socialismo, izquierda), así como al avance de la ciudad virtual y el desplome de la ideología, fenómenos que inhibieron el análisis de una intelectualidad sorprendida por la velocidad de las transformaciones. Entre los factores políticos se cuentan hechos de gran intensidad como la derechización de Occidente (1979), el derrumbe del socialismo de Estado (1989), la invisibilidad en que cayeron los movimientos de liberación nacional, el fin del Estado benefactor y del taylorismo, la aparición de un mundo bipolar, los efectos de la tercera revolución científico-técnica, los avances de la informática y las nuevas formas de acumulación de capital, entre otros. 
dable refuerzo en la crisis de las ciencias de la sociedad, al extremo que, a principios de los noventa, era acuñado por A. Giddens el concepto de crisis estable 4 en las ciencias sociales, opinión interesada en la medida que aparecía la tercera vía, una fórmula de convivencia entre el proyecto socialdemócrata y el neoliberal.

Ahora bien, no obstante la fuerza del impacto, por doquier se levantaron barreras de contención tras algunos años de lucha por la sobrevivencia. A manera de ejemplo podemos realzar las producciones del ecuatoriano A. Cueva y de los peruanos Flores Galindo y A. Quijano; ${ }^{5}$ saliendo de la región, otro lugar memorable de resistencia cultural lo representaron las resoluciones del $\mathrm{V}^{\mathrm{o}}$ Congreso de Sociología Centroamericana en 1982; en Chile -en plena dictadura- apareció el Grupo ANDES, reclamando espacio para la teoría crítica (1983), pero sucedió lo mismo en Bolivia tras la derrota de Calamarca. Aún más, el mismo año en que se proclamaba la crisis estable de las ciencias sociales, el argentino A. Dabat publicaba en México Capitalismo mundial y capitalismos nacionales, primer volumen de un trabajo sobre la conformación y desarrollo histórico del capitalismo mundial. ${ }^{6}$

Aquellos también fueron tiempos complejos en lo que a la historia se refiere. Fukuyama pronto habría de extender el certificado de defunción a la disciplina luego de publicar El fin de la historia, ofensiva contrarrestada en ese campo sólo hace algunos años, cuando el historiador británico, E. Hobsbawm en su Manifiesto para la renovación de la historia (2004), denunció que la disciplina se encontraba severamente afectada en su capacidad de entender el mundo por medio de una investigación racional sobre el curso de las trasformaciones humanas. Según el autor de Historia del Siglo XX, la conjunción de relativismo y consenso había preparado el camino para la valorización de la identidad (trasladando el estudio desde lo que ocurrió a lo que le ocurrió al grupo), señalando además que, desde 1985, esta tendencia se había acentuado

${ }^{4}$ Anthony Giddens, Modernidad e Identidad del yo, 1994, Barcelona, Península.

${ }^{5}$ Agustín Cueva, El desarrollo del capitalismo en América Latina, 1978, México, Siglo XXI; Alberto Flores Galindo, Aristocracia y plebe. Lima, 1760-1830. Estructura de clases y sociedad colonial, 1984, Barcelona, Crítica; Aníbal Quijano, Modernidad, identidad y utopía en América Latina, 1988, Lima, Ediciones Sociedad y Política.

${ }^{6}$ Alejandro Dabat, Capitalismo mundial y capitalismos nacionales, 1994, FCE/UNAM, México. 
cuando se produjo "la transición de los estudios cuantitativos a los cualitativos, de la macro a la microhistoria, del análisis estructural a los relatos, de lo social a los temas culturales"?

Ahora bien, en el caso chileno se juntaron dos tendencias de alto impacto en la historiografía crítica. Por un lado, constatamos los efectos del shock político y cultural al que hemos hecho referencia, aunque, por otra parte, sus errores fueron determinantes. Producto de la propuesta proveniente de la ciencia social militante de los sesenta/setenta, ${ }^{8}$ la historiografía chilena hizo suyo el supuesto proveniente de la Conferencia de los '81, en el sentido de que el mundo experimentaba la transición del capitalismo al socialismo a escala mundial, de manera que, al derrumbarse el socialismo, gran parte de esa historiografía perdió el punto de referencia internacional, lo que explica que un voluminoso cuerpo de reflexión caminara sin la orientación del factor internacional, cobrando la historia de Chile una especie de vida propia, referida a sí-misma, sin el referente externo.

Como puede apreciarse, el panorama descrito fue propicio para el abandono teórico de la visión de conjunto, ralentizándose la productividad que caracterizó a nuestras ciencias sociales. Sin embargo, estos últimos años ha comenzado a revertirse la situación con obras como la del argentino F. Delich, quien con su Repensar América Latina se preguntaba por qué en una zona en plena modernización, en la que sus pueblos se habían reencontrado con la democracia y habían crecido las expectativas de vida, pudiese haberse acentuado la brecha entre ricos y pobres. ${ }^{9}$ Por su parte, el pensamiento católico progresista también se hizo presente con textos como La América Latina del siglo XXI de Methol y Metalli. ${ }^{10}$ A éstos se suma la producción reciente de la vitalizada historia económica que emergió en Barcelona y

${ }^{7}$ Eric Hosbsbawm, "Manifiesto para la renovación de la historia”, en www.rebelion.org/ mostrar.php?...eric\%20 Hobsbawm...

${ }^{8}$ Alejandro Chelén, "Conferencia de los 81", en Documentos e Informes emanados de Plenos y Congresos del Partido Comunista de Chile, 1963, Santiago, PLA. Para una "aplicación" de la teoría, Enrique Correa, "La situación internacional", en Unidad Proletaria, núm. 2, 1972, Santiago, p. 8 ss.

${ }^{9}$ Francisco Delich, Repensar América Latina, 2004, Barcelona, Gedisa.

${ }^{10}$ Alberto Methol y Alver Metalli, La América latina del siglo XXI, 2006, Buenos Aires, Edhasa. 
Uruguay, ${ }^{11}$ recuento en el que no puede dejar de mencionarse el esfuerzo por estudiar a las sociedades latinoamericanas realizado en Chile por J. Chonchol. ${ }^{12}$ Otro tanto podría señalarse respecto a la propuesta de repensar la idea de América Latina desde una arqueología decolonial, como lo planteara hace poco W. Mignolo, ${ }^{13}$ cabeza visible de una nueva manera de entender la región. En fin, estamos ante un importante renacer de la producción teórico-crítica; tanto, que al momento de redactarse esta comunicación aparecieron tres nuevos textos. ${ }^{14}$

En fin, retomando la idea original, en un contexto de crisis de la economía-mundo, el debate sobre el retraso de nuestra América comienza a reaparecer en el horizonte, acompañado de una dimensión de carácter holístico, como son las propuestas de los teóricos del institucionalismo, de los estudios postcoloniales y del renacer marxista. De manera que puede constatarse, empíricamente, la reaparición del pensamiento crítico, rompiéndose la cadena autoritaria y neoliberal.

\section{La teoría emergente}

La teoría crítica y el movimiento democrático-popular, insistimos, no sólamente fueron derrotados políticamente, también sucumbieron en el plano de la cultura y la teoría social. El tratamiento de shock no fue un fenómeno económico; vino aparejado con una marejada cultural que impulsó e impuso un nuevo tipo de percepción de los fenómenos sociales a partir del mercado. En ese contexto, el colapso del marxismo latinoamericano, de la teoría de la dependencia, del pensamien-

${ }^{11}$ María del Pilar Rubio y Reto Bertoni (comp.), Energía y desarrollo en el largo siglo XX. Uruguay en el marco latinoamericano, 2008, Uruguay, UniversitatPompeu Fabra/Facultad de Ciencias Sociales Universidad de la República, Uruguay.

${ }^{12} \mathrm{Al}$ regreso de un largo exilio, Jacques Chonchol, ex ministro del presidente Allende, instaló con apoyo de La Sorbona y el Instituto de Altos Estudios para América Latina, un doctorado en una Universidad resistente en Chile (ARCIS), donde alcanzó a publicar la revista América Latina.

${ }^{13}$ Walter Mignolo, La idea de América Latina, 2007, Barcelona, Gedisa, p. 12.

${ }^{14}$ Margarita López, Carlos Figueroa y Beatriz Rajland (editores), Temas y procesos de la historia reciente de América Latina, 2010, Arcis/Clacso, Santiago/Buenos Aires; Frank Gaudichaud, El volcán latinoamericano: izquierdas, movimientos sociales y neoliberalismo al sur del Río Bravo, 2011, Santiago, Escaparate; Mario Rapoport y Noemí Brenta, Las grandes crisis del capitalismo contemporáneo, 2010, Buenos Aires, Capital Intelectual. 
to cepaliano, de la teología de la liberación y diversas formas de nacionalismo de izquierda fue inapelable, de manera que lo más aconsejable era esperar nuevos avances teóricos y, mientras tanto, repensar la región de la teoría. En esas circunstancias, un segundo muro de contención lo constituyeron una serie de obras signadas por el interés individual y el talento de algunos autores.

Motivo de gran aliciente en la búsqueda de respuestas sobre el cambio operado fue el texto de A. Ferrer, Historia de la Globalización. ${ }^{15}$ Algunos años después, un autor relevante (aunque no sudamericano), D. Landes, entregaba un libro en el que se persistía en la idea de estudiar la evolución de los últimos 500 años y el terrible impacto que significó la expansión europea para los países de la periferia. Al respecto se preguntaba:

¿Cuán grande es la brecha entre ricos y pobres y qué transformaciones está sufriendo? Muy somera y brevemente: la diferencia de ingreso per capita entre el país industrial más rico, digamos Suiza, y el país no industrial más pobre, Mozambique, es aproximadamente de 400 a 1 . Hace doscientos cincuenta años, esta brecha entre los más ricos y los más pobres era tal vez de 5 a 1; y la diferencia entre Europa y, digamos el Este o el sur de Asia (China o India) era de alrededor de 1,5 o 2 a $1 .{ }^{16}$

A esta interrogante podríamos agregar que la brecha seguía creciendo y con agravantes, porque algunos países no sólo no crecieron, sino que se volvieron más pobres, al extremo de que, hace tan sólo un par de años, algunos sociólogos comenzaron a calificar a algunos de ellos como “países residuales" (Afganistán), en el entendimiento que no tenían nada que ofrecer a la economía globalizada, como no fuera "turismo de guerra". En fin, de este somero recuento no puede excluirse el balance de la teoría de la dependencia de T. Dos Santos ${ }^{17}$ otro salto lo constituyeron la publicación de la Historia General de América Latina

${ }^{15}$ Aldo Ferrer, Historia de la Globalización, 1996, Buenos Aires, vol. I-II, FCE.

${ }^{16}$ David S. Landes, La riqueza y la pobreza de las naciones, 1999, Buenos Aires, Javier Vergara Editor, p. 23.

${ }^{17}$ Theotônio Dos Santos, La Teoría de la Dependencia, 2003, Buenos Aires, Plaza \& Janés. 
de la UNESCO,${ }^{18}$ todo un aliciente para recuperar el holismo historicista y la producción de CLACSO bajo las conducciones de A. Borón y E. Sader. Ahora bien, entre tanto habían ido apareciendo o revitalizándose nuevas lecturas.

Una interesante reflexión provino de los teóricos de la "Escuela institucionalista", liderados por el premio alternativo de economía D. North ${ }^{19}$ y reforzado por discusiones con autores como Maddison, Thorp, Ocampo y otros. ${ }^{20}$ Contribuciones a las que ahora debe agregarse la del chileno C. Yánez quien, buscando las causas del rezago de nuestra América, concluye que éste se produjo entre 1750-1850 debido a la forma que asumió el sistema colonial implantado por españoles y portugueses. Acotando el asunto a la presencia española, afirma que España no sólamente trasladó la hueste indiana, sino el acervo cultural, idioma, religión y visión-de-mundo. Además, injertó su propia estratificación social, la servidumbre y la forma de división de la tierra; y, por si fuera poco, trajo la concepción del encuentro con la riqueza fácil, por cuanto la lejanía del poder central permitió el famoso principio que estipulaba "la ley se acata pero no se cumple", institucionalizando así la arbitrariedad, forjadora-por lo demás-de inseguridad y desconfianza en las empresas y en los invasores. Agreguemos, indica Yañez, el ocio especulativo, la concentración de la propiedad, la

${ }^{18}$ Con todo propiedad, Germán Carreras en la Introducción al volumen 5 señala: "A lo largo de sólo medio milenio, América Latina se ha conformado como una de las grandes regiones geo-culturales del mundo. Su unidad territorial es evidente. Su significación en el escenario mundial de la cultura no requiere de nueva argumentación. Su esfuerzo sostenido y crecientemente exitoso por constituirse como un conjunto de sociedades modernas, democráticas y orientadas hacia niveles cada día más altos de bienestar, es reconocido. En suma, América Latina es una realidad que puede ser historiada como totalidad. Por eso, hemos escrito esta Historia General de América Latina". Al respecto, Historia General de América Latina, 2003, España, Editorial Trotta.

${ }^{19}$ Douglass C. North, Instituciones, cambio institucional y desempeño económico, 1995, México, FCE.

${ }^{20}$ Angus Maddison, "The World Economy: A Millennial Perspective", 2001, París, Centro de Desarrollo de la OCDE; Rosé-Mary Thorp, "Las economías latinoamericanas 19391950”, en Lelie Bethell, Historia de América Latina: Economía y Sociedad desde 1930, 2000, Barcelona, vol. 11, Crítica.

José A. Ocampo, “América Latina y la economía mundial en el siglo largo”, Conferencia especial para el $70^{\circ}$ aniversario del Trimestre Económico, 2004, México. 
desigualdad, el rezago respecto al mercado mundial (en formación), la baja densidad poblacional, el nulo aliciente para la creación del mercado de trabajo, la ausencia de industrialización y el estancamiento a largo plazo. Esta tendencia habría conducido finalmente al rol que se asignó al Estado, que terminó reemplazando a los agentes económicos. ${ }^{21}$

Para la Escuela institucionalista, ${ }^{22}$ las consecuencias a largo plazo de este tipo de evolución favorecieron la formación de economías de alto costo transaccional, con mercados irregulares, desigualdad, exclusión, derechos poco trasparentes y feble institucionalidad, aspectos propicios para una economía rentista, más que competitiva. De este balance se desprende, entonces, la propuesta de explorar la naturaleza de las instituciones (a largo plazo) como creadora de estímulos en la economía, para aprovechar la oportunidad de ganancia. En fin, el objeto de estudio pasa por enfocar la función de las instituciones en el desempeño económico, habida cuenta de que, como señala el propio North, no existe un "marco analítico que integre el análisis institucional en la economía política y en la historia económica". ${ }^{23}$ Alejados de la teoría neoclásica, a la cual critican la tendencia a la distribución de recursos en un momento determinado, buscan explicar el cambio en el largo plazo y en la estabilidad institucional, postulados que en cierto modo imperaron en Chile durante los gobiernos de la Concertación de Partidos por la Democracia. En ese sentido, resulta sintomático constatar que ni siquiera el fracaso político en las elecciones presidenciales de 2010 han puesto un manto de duda sobre la tendencia, al mantenerse inalterable la estabilidad institucional y el funcionamiento del modelo económico, no obstante las reformas anunciadas para profundizar las privatizaciones.

${ }^{21}$ César Yánez, “Atraso y desigualdad. La perspectiva de historia económica”, en Instituciones y Desarrollo, 2000, Barcelona.

${ }^{22}$ Efectivamente, estamos hablando de una escuela compuesta por economistas-historiadores e historiadores economistas. Realizan congresos, sostienen publicaciones y han desarrollado tres lugares de concentración: Estados Unidos (MIT), Barcelona (Universidad de Barcelona), y Uruguay (Universidad de la República).

${ }^{23}$ Op. cit., p. 13. 
Por otra parte, por esos mismos años y desde los "Estudios poscoloniales", han emergido nuevas formas de reflexión. Aun cuando este es un tema mayoritariamente radicado en la academia anglo-norteamericana, no ha dejado de tener repercusiones en el debate regional; autores como Appadurai, Bhabha, Chakrabarty, Clifford, Guha, Hall, Said, Spivak, son parte de ese paisaje intelectual, ${ }^{24}$ así como algunos de los conceptos de uso corriente en sus reflexiones (desterritorialización, diáspora, mestizaje). Ahora bien, la matriz ideológica poscolonial es un tanto anterior a su reciente boom. Estos estudios son tributarios del debate epistemológico posterior a 1968; por lo tanto, se entroncan (habidas excepciones) con la propuesta postmoderna, de manera que el giro poscolonial tiene en la base de su fundamentación el cuestionamiento a los principios del iluminismo. La presencia de conceptos fundantes de la obra de autores como Derrida y Foucault está fuera de toda duda (fin de la filosofía, muerte del sujeto, disolución de la idea de la verdad). En fin, la deslegitimación de la crítica de la razón, acompañada por el rechazo, ahora, del metarelato, culminó con un marcado antihumanismo, vieja herencia altusseriana, que terminó por disolver a Marx y la crítica de capitalismo (ahora globalizado).

Desde otro ángulo, desde los "Estudios culturales", han hecho importantes aportes para reformular el latinoamericanismo, sobre todo luego de las fracturas teóricas que siguieron al quiebre del socialismo real. Desde numerosas ópticas, un importante grupo de intelectuales, situados en los márgenes-del-sistema y alejados de los grandes paradigmas, armados de una gran variedad temática, teórica y metodológica, iniciaron cruces interdisciplinarios que redundan en nuevas miradas sobre el continente. La desigualdad, la explotación y la mar-

${ }^{24}$ A. Appadurai, Modernity at Large. Cultural Dimensions of Globalization, 1966, Minneapolis, University of Minnesota Press; H. Bhabha, El lugar de la cultura, 2002, Buenos, Aires, Manantial; D. Chakrabarty, Provincializing Europe, Postcolonial Thought and Historical Difference, 2000, Princeton, Princeton University Press; J. Clifford, Roots. Travel and Translation in the Late Twentieth Century, 1977, Harvard, Harvard University Press; R. Guha, Las voces de la historia, 2000, Barcelona, Crítica; Stuart Hall, "Estudios culturales: Dos Paradigmas”, en Causas y Azares, 1994, Buenos Aires, núm. 1; Gayatri Spivak, “¿Puede hablar el sujeto subalterno", en Orbis Tertius, La Plata, 1999, Revista de Teoría y Crítica Literaria, año III, núm. 6. 
ginación siguen siendo temas señeros, atrapados ahora en las limitaciones que presenta la provisionalidad. Como señala M. Moraña en el prólogo al texto, Nuevas perspectivas:

Esta misma pluralidad de enfoques y temáticas hace evidentemente que este libro no pretende ofrecer una propuesta única sino aproximaciones parciales y hasta provisionales - a veces contrapuestas-a aspectos muy dispares de la cultura latinoamericana: el de la lectura e incorporación de tradiciones y genealogías en debates actuales; el que vincula problemáticamente cuestiones de clase, raza y género; el que atiende a los tránsitos de la migración y la consecuente reterritorialización de sujetos y prácticas culturales; el que enfoca el lugar de las ideologías en la definición de agendas culturales que se enfrentan al vaciamiento en la posmodernidad. ${ }^{25}$

Ahora bien, el peso euro-norteamericano, la distancia del problema de la relación Estado/nación, el poco entusiasmo que muestran ante el concepto epistemología y el acercamiento a los problemas de la identidad por sobre el conflicto social, sitúa estas contribuciones más en el plano de un discurso estético al que falta una teoría económica, mayormente visible en tiempos de crisis. Así, también, la cercanía con el tema cultural y la lejanía con el tema del capital monopólico, impiden radicalizar la crítica del "capitalismo tardío". Pero, por otra parte, siendo un objetivo de esta intelectualidad contribuir al pensamiento crítico, se abre un umbral de confluencia para la construcción de nuevos movimientos antisistémicos. En esa dimensión merece una mención especial la perspectiva que presenta N. Richard, autora de un trabajo que, en sus palabras, ha recorrido múltiples escenarios; esto es, enfrentado dictaduras, proponiendo rupturas epistemológicas, desarrollando teoría feminista, impulsando al intelectual a ejercer la crítica, entendida como:

Una operación de desnaturalización del sentido. Mostrar, revelar que los Signos, las formas no son nunca inocentes, ni las palabras, ni las imágenes, que la realidad no habla por sí misma, que cobra sentido a través de mediaciones discursivas y que esas mediaciones discursivas

${ }^{25}$ Mabel Moraña (ed.), Nuevas perspectivas desde/sobre América Latina: el desafio de los estudios culturales, 2000, Santiago, Editorial Cuarto Propio, p. 9. 
deben ser desmontadas y remontadas [...] para quebrar la neutralidad pasiva del sentido. ${ }^{26}$

En este recuento, y en ese matiz, juegan un papel importante los estudios referidos a la "colonialidad del poder", también orientados a la búsqueda, como señala E. Lander, de "alternativas a la conformación profundamente excluyente y desigual del mundo moderno". ${ }^{27}$ Se trata de la búsqueda de nuevas respuestas a viejos problemas, de detectar los puntos débiles en los anteriores análisis como, por ejemplo, la ausencia de la naturaleza en el análisis de la creación de riqueza. Al no estar presentes la naturaleza, los recursos, el espacio y el territorio en el desarrollo histórico del capitalismo, éste aparece como un proceso diferenciado de Europa, borrando así el papel del colonialismo en la historia, en circunstancias que la modernidad europea y la organización de la colonización son parte de un proceso iniciado, a lo menos, en el siglo XV; al ignorarse estos factores, la responsabilidad europea en el rezago se diluye.

\section{El sistema-mundo}

Entre las nuevas producciones que están entregando insumos importantes para revertir la tendencia ocupa un lugar importante la teoría del sistema-mundo, cuya importancia consiste en ofrecer nuevas consideraciones sobre la evolución histórica del capitalismo, acompañada de sugerencias para la acción política a escala global.

En la madurez de sus vidas, autores como I. Wallerstein, G. Arrigí, y otros, están entregando sugerentes pistas para revisar la historia universal; su contribución, complementada con el pensamiento de algunos autores latinoamericanos que sostienen la teoría periferia/centro, provenientes tanto de la CEPAL (R. Prebich) como de la teoría de la de-

${ }^{26}$ Palabras en la presentación del texto, Campos Cruzados. Crítica cultural, latinoamericanismo y saberes al borde, 2009, La Habana, Casa de las Américas.

${ }^{27}$ Edgardo Lander, "Ciencias Sociales: saberes coloniales y eurocéntricos", en E. Lander (comp.), La colonialidad del saber: eurocentrismo y ciencias sociales, 2000, Buenos Aires, CLACSO/UNESCO, p. 12. 
pendencia (A. Gunder Frank), podrían proyectarse hacia la constitución de un nuevo campo teórico en nuestra América en la medida que están impulsando la integración crítica de matrices relativas a la materialidad societal, como las concebidas por Marx y Braudel. ${ }^{28}$ Ahora bien, al historiador francés corresponde la creación del concepto "economíamundo", desarrollado en su intento por relacionar la historia del capitalismo con la historia de la expansión europea. En su consideración, la universalidad de Europa consistió en haber dado lugar a una economíamundo y a una tradición cultural, proceso de producción de conocimiento que le llevó incluso a postular una diferencia entre economía mundial (entendida como economía mundial en su totalidad, como "el mercado de todo el universo") y economía-mundo (entendida como "la economía de sólo una porción de nuestro planeta"). A partir de estas consideraciones, la obra de I. Wallerstein establecería una importante diferencia porque en su opinión, desde el siglo XVI, no habría más economía-mundo que la europea, en tanto que, para Braudel, el mundo estaría dividido desde la antigüedad en zonas económicas que habrían coexistido. Sustantiva diferencia que se encuentra en la base de la nueva teoría.

Marx, sin duda alguna, abrió el camino. En su esfuerzo por entender el desarrollo del capitalismo, puso en circulación una idea central al señalar que antes de que se iniciara la acumulación capitalista existió un período previo de acumulación originaria, "una acumulación que no es resultado, sino punto de partida del régimen capitalista de producción". ${ }^{29}$ Le correspondió al pensador alemán descubrir los mecanismos de la acumulación originaria y con ellos los primeros pasos del capitalismo; es decir, los mecanismos que caracterizan la historia universal desde el siglo XVI. La acumulación originaria, entendida como el proceso histórico de disociación entre el productor y los medios de producción, no es sino la prehistoria del capital brotado desde la sociedad feudal. Ahora bien, esto nos pone ante un dilema complejo: si tomamos en cuenta que en nuestra América difícilmente podemos hablar de la existencia de feudalismo, debe repensarse el fenóme-

${ }^{28}$ Fernando Braudel, La Dinámica del Capitalismo, 1985, Madrid, Alianza Editorial.

${ }^{29}$ Carlos Marx, El Capital,1966, México, t. I, FCE, p. 607. 
no de la acumulación originaria a escala continental. En ese sentido, en un nuevo espacio/tiempo, caracterizado por un nuevo patrón de poder mundial, coincidieron el impacto racial de la conquista con el despliegue de nuevas formas de control del trabajo y los recursos en torno a la expansión del mercado-mundo que emergía.

Esto implica que en ese mundo colonizado se dieron dos procesos simultáneos. Uno contribuyó a la acumulación originaria europea y, por lo tanto, a la expansión de un nuevo sistema-mundo; el segundo proceso, como afirma el mexicano, E. Semo, ${ }^{30}$ condujo a la desacumulación originaria de la región, por cuanto la acumulación no solamente se concentró en uno de los polos del sistema: en el otro generó una desacumulación de tal naturaleza que frenó el desarrollo de los territorios conquistados al impedir que el excedente económico producido en la periferia se transformara en capital. Por eso, a las sociedades de América se les impidió transitar al tipo de capitalismo que emergía en Europa desde el siglo XVI. Ese excedente que pudo haber transformado a México y Perú en potencias finalmente se transformó en el impedimento que explica el actual rezago respecto a los países centrales.

Profundizando, desde esta perspectiva en la exploración histórica universal, I. Wallerstein dará otro paso importante al señalar que, hacia fines del siglo XV y principios del XVI, habría emergido una economía-mundo europea:

A finales del siglo xV y principios del XVI nació lo que podríamos llamar una economía-mundo europea. No era un imperio, pero no obstante era espaciosa como un gran imperio y compartía con él algunas características. Pero era algo diferente y nuevo. Era un tipo de sistema social que el mundo en realidad no había conocido anteriormente, y que constituye el carácter distintivo del moderno sistema mundial. Es una entidad económica, pero no política, al contrario que los imperios, las ciudadesEstado y las naciones-Estados. De hecho precisamente comprende dentro de sus límites (es difícil hablar de fronteras) imperios, ciudades-Estados, ${ }^{30}$ Enrique Semo, Historia del capitalismo en México. Los orígenes.1521/1723, 1973, México, ed. Era, p. 232 ss. 
y las emergentes "naciones-Estado". Es un sistema mundial, no porque incluya la totalidad del mundo sino porque es mayor que cualquier unidad política, jurídicamente definida. Y es una economía-mundo debido a que el vínculo básico entre las partes del sistema es económico, aunque esté reforzado en cierta medida por vínculos culturales y eventualmente, como veremos, por arreglos políticos e incluso estructurales y confederales. ${ }^{31}$

Desde este punto de vista, podría decirse que siempre existieron economías-mundo que terminaron por transformarse en imperios (China, Roma). Ahora, una de esas economías-mundo, situada en una coyuntura favorable logró experimentar el gran salto. Hacia 1300-1450 en el contexto de la "gran crisis feudal" (guerras de nobles, levantamientos feudales, cambio climático, agotamiento de la ganancia por agotamiento de la tierra, expansión de la pandemia), Portugal se puso a la cabeza de Europa, seguido por España, que tuvo la gran posibilidad cuando los Habsburgo, bajo la conducción de Carlos V, intentó hegemonizar la región, ensayo fracasado hacia 1557, cuando Felipe II declaró en bancarrota al imperio. Mientras tanto, América comenzaba a vivir los efectos de la expansión española porque las colonias fueron entendidas como extensiones de España y transformadas en economías de exportación.

Tras este análisis en que se combinan Marx/Braudel/Wallerstein aparece la propuesta wallerstiana de develar la existencia de un sistemamundo histórico, acudiendo a un enfoque sistémico que, combinando la dicotomía desarrollo-en-el-centro y rezago-en-la-periferia, explicita el espacio-mundo en que se mueve la trama, el tiempo que lo contiene (la larga duración), detectando también la inexistencia de una estructura política dominante, complejo histórico que terminó por extenderse a la totalidad planetaria a fines del siglo XIX y que dio forma a una relación asimétrica cristalizada en el contrapunto entre centro y periferia, lugar de la apropiación de plusvalía a escala mundial. El aporte de Wallerstein sería incomprensible si se dejara de mencionar la contribución de A. Gunder Frank, ${ }^{32}$ especialmente su teoría sobre la depen-

${ }^{31}$ Immanuel Wallerstein, El moderno sistema mundial. I la agricultura capitalista y los orígenes de la economía-mundo europea en el siglo XVI, 1989, México, ed. Siglo XXI, p. 21.

${ }^{32}$ A. Gunder Frank, El subdesarrollo del desarrollo: un ensayo autobiográfico, 1991, Madrid, IEPALA. 
dencia, entendida como el producto histórico que explica las formaciones sociales capitalistas-dependientes desde las conquistas europeas del siglo XVI; sociedades en que los grupos dominantes terminaron por convertirse en "lumpen-burguesía", donde la única salida a su situación era el cambio social profundo, dado que ni la industrialización sustitutiva, ni la promoción de la industria exportadora, ni el libre intercambio han logrado neutralizar: la extracción de plusvalía.

Otras importantes y novedosas contribuciones a la expansión de la teoría-mundo son las que presenta G. Arrighi, para quien el capitalismo no parte de relaciones socioeconómicas, sino desde lo que denomina "intersticios", mediante los cuales se conectaron las economías, gracias al comercio entre Europa y Asia desde fines del siglo XIII. ${ }^{33}$ Por este camino llega al análisis de la penetración del capitalismo en las colonias, poniendo atención en la acumulación primitiva colonial y su conexión con los modos de producción comunitarios, vía que le condujo a reformular la teoría del imperialismo desde la larga duración, proponiendo para ello dos criterios de periodización: el estudio de los rasgos de la potencia hegemónica y el de los rasgos del imperialismo que organiza a la potencia. Por su parte, S. Amir coincide con la existencia de un sistema mundial y concluye que lo que hemos denominado rezago-en-la-periferia es producto de la polarización del sistema mundial, que se reproduce a través de un ajuste estructural permanente en la periferia, lo que impide a ésta dar el salto cualitativo, fracasando hasta ahora en todos los intentos de desmantelamiento del sistema, como lo demuestran la apertura al mercado mundial del liberalismo neocolonial, el fracaso de la modernización del nacionalismo radical, que emergió tras la Conferencia de Bandung (1955), así como el de la URSS. En este contexto, encuentra sentido la propuesta para la construcción de una teoría de la acumulación a escala mundial, para el desarrollo de las acciones que conduzcan a la construcción de un mundo policéntrico ${ }^{34}$ que abra espacios a una nueva sociedad a escala mundial.

${ }^{33}$ Giovanni Arrighi, El largo siglo XX, 1999, Madrid, Akal.

${ }^{34}$ Samir Amir, El capitalismo en la globalización, 2002, Barcelona, Paidos. 
Se torna imprescindible (re)ubicar el lugar que ocupa América en el orden mundial. Por cierto, la producción latinoamericana también está presente en la proyección de la teoría del sistema-mundo, -existe una discusión centenaria sobre el lugar que ocupa América en el orden mundial y sobre la cual numerosos autores (Las Casas, Hegel, Marx) nos han ubicado desde una posición eurocéntrica. Sin embargo, correspondió a un mexicano, E. O' Gorman, ${ }^{35}$ en 1958, haber deslindado aguas con el centenario concepto descubrimiento; propuso, en su reemplazo, el argumento de la invención de América, entendiendo que el primero justificó la apropiación del continente. Descubrimiento e invención, entonces, constituyen paradigmas distintos; el descubrimiento, integrado en el imaginario cristiano de Europa, constituye una perspectiva de la historia universal ligada a una Europa en expansión; en tanto que la invención remite a la idea de colonia, a la existencia de territorios que no forman parte de la historia del hombre blanco. Casi simultáneamente, en el marco de la polémica sobre los modelos de desarrollo, aparecieron las propuesta "desarrollistas" ${ }^{36}$ que reclamaban una estrategia para el desarrollo regional, línea que en la $9^{\circ} \mathrm{Confe-}$ rencia de Cancilleres de América Latina, realizada en Bogota en 1948, llegó a exigir una Plan Marshall latinoamericano, petición rechazada por los Estados Unidos.

A principios de los sesenta la Teoría de la Dependencia pondría otra nota en el reclamo de nuestra América por romper las ataduras de medio milenio, una vez atemperado el furor de la CEPAL, bajo el doble impacto de la revolución cubana y de lo que se consideraba como el fracaso del desarrollismo; se impuso una nueva fórmula de pensamiento para comprender nuestras realidades. Ahora bien, desde el punto de vista de la historia de las ideas, Gunder Frank (Capitalismo y Subde-

\footnotetext{
${ }^{35}$ Edmundo O' Gorman, La invención de América: el universalismo de la cultura occidental, 2006, México, FCE.

${ }^{36}$ Indudablemente, el gran animador del pensamiento de la CEPAL fue el argentino Raúl Prebisch. Ahora bien, el concepto 'desarrollismo' es amplio e impreciso porque existieron diversas corrientes, todas ellas basadas en el combate al subdesarrollo. Así, tenemos la teoría del desarrollo con crecimiento (C. Furtado, I. Adelman), la del desarrollo secuencial, aquella que visualizó fases consecutivas para alcanzar el nivel de los países desarrollados (W. W. Rostow, A. W. Lewis) y la teoría de el desarrollo como cambio estructural (P. Paz).
} 
sarrollo en América Latina), R. Stavenhagen (Siete Tesis equivocadas sobre América Latina) y S. Bagú (Economía de la sociedad colonial), sometieron complejos temas a debate, como el del carácter del capitalismo latinoamericano, el del cambio social y la forma que asumía la crisis, aliciente para una fructífera discusión que, según Cardoso y Faleto, se caracterizaba porque "la materia prima de la cual se parte es la lucha política y la lucha económica tal cual se libran en la superficie del proceso histórico, como lucha nacional y antiimperialista", impacto que prontamente dio pie para el desarrollo de -a lo menos- tres tendencias. ${ }^{37}$ Ahora bien, siendo este un serio esfuerzo teórico-metodológico para entender América Latina no logró constituir una sola escuela de pensamiento, el peso de los factores internacionales y las definiciones políticas locales debilitaron la propuesta; además, las repercusiones del ciclo autoritario terminaron por eclipsarla, puesto que con la ola autoritaria se impuso un nuevo período inspirado en la corriente neoclásica monetarista de la Escuela de Chicago.

Sin embargo, la noción periferia/centro se había ampliado a la calidad de concepto integrador de la historia universal, aunque, quedaba un cabo suelto: el factor poscolonial. De manera que, cuando a fines de los ochenta, A. Quijano recuperó el tema de la colonialidad, el tema oscuro de la modernidad, el encaje de las piezas del rompecabezas de la historia experimentó un salto, empujado desde nuestra periferia, porque quedó díafanamente clara, como nunca, nuestra ubicación histórica en la globalización:

La globalización en curso es en primer término, la culminación de un proceso que comenzó con la constitución de América y del capitalismo colonial/moderno y eurocentrado como un nuevo patrón de poder mundial. Uno de los ejes fundamentales de ese patrón de poder es la clasificación social de la población mundial sobre la idea de raza,

${ }^{37}$ La Teoría de la Dependencia también tuvo diversos entendimientos. Entre otros, el dependentismo dialéctico (F. Weffort, T. A. Vasconi), el dependentismo puro (Th. Dos Santos, V. Bambirra) y en cierta manera el dependentismo desarrollista (Sunkel). Para una visión global, Theotonio Dos Santos, La teoría de la dependencia. Balance y perspectivas, 2003, Buenos Aires, Plaza\& Janes. 
una construcción mental que expresa la experiencia básica de la dominación colonial. ${ }^{38}$

El planteamiento de Quijano está renovando la historia de América, entendido ahora como el lugar y tiempo de convergencia de dos procesos: el de la formación de relaciones sociales basadas en el racismo, de su articulación con formas de trabajo y su control (esclavitud, servidumbre, producción mercantil). El capitalismo mundial, entonces, será una combinación de expansión/colonialismo/eurocentrismo que en nuestro caso imbricó dos áreas geoculturales, cruzadas por relaciones de superioridad/inferioridad. Siguiendo estas inquietudes intelectuales, E. Düssel aporta a la discusión pensando filosófica y racionalmente la crisis del sistema-mundo que, ahora globalizado, llega hasta el "último rincón de la Tierra, excluyendo, paradójicamente, a la mayoría de la humanidad". ${ }^{39}$ Este esfuerzo llevará al autor a intentar ampliar la historia eurocéntrica-norteamericana a panoramas más amplios de "mundialidad". Por su parte, E. Lander ${ }^{40}$ dará otro paso en el cuestionamiento de la historia europea como historia universal al señalar que la conquista representa un momento que fusiona la modernidad europea con la organización colonial de nuestros territorios, al tiempo que traslada los saberes, las lenguas, la memoria y el imaginario, vaciando la autoconciencia americana. Tendencia de la cual pocos han escapado en América, ¿tal vez por eso, durante el siglo XX la izquierda latinoamericana, abrazada al "materialismo histórico", debatió sobre dos modelos de cambio: la revolución democrático-burguesa o la revolución socialista?

Finalmente, cobra una dimensión importante desde esta perspectiva historicista la contribución del argentino W. Mignolo, empeñado en "construir una arqueología decolonial de la idea de América Latina" ${ }^{41}$

${ }^{38}$ Aníbal Quijano, "Colonialidad del poder, eurocentrismo y América Latina”, en La colonialidad del saber: eurocentrismo y ciencias sociales, 2000, Buenos Aires, CLACSO, p. 201.

${ }^{39}$ Enrique Dussel, Ética de la liberación en la edad de la globalización y de la exclusión, 1998, México/Madrid, Editorial Trotta, UAMI/UNAN, p. 11.

${ }^{40}$ Edgardo Lander, "Ciencias sociales: saberes coloniales y eurocéntricos", en Edgardo Lander (comp.), La colonialidad del saber: eurocentrismo y ciencias sociales, 2000, Buenos Aires, CLACSO/UNESCO.

${ }^{41}$ Walter D. Mignolo, La idea de América Latina, 2007, Barcelona, Gedisa, p. 12. 
El intento por construir una nueva visión de la región se suma como aporte sustantivo, especialmente cuando en Bolivia y Ecuador las luchas indígenas están contribuyendo al multiculturalismo y a la aparición de nuevas nociones sobre el Estado (el Estado plurinacional). Entonces, la vieja discusión sobre la esencia de América Latina vuelve a ser tema de discusión.

En suma: en la edad de la globalización, cuya cultura de la fragmentación ha impactado la visión holística de la historia, se hace necesaria una mirada globalizada de la historia que permita entender los trasfondos por los que transita la humanidad. De manera que si aceptamos la posibilidad de existencia de una teoría emergente, la del sistema-mundo, entendida como el punto de concentración de múltiples "semi-verdades", teoría entendida como el estudio del sistema social en interrelación con el avance del capitalismo, tanto en el centro como en la periferia, visualizando que la unidad de análisis central no debería ser el Estado-nación o la sociedad nacional, sino el sistemamundo en su conjunto, podríamos entender que la economía-mundo es un sistema basado en la desigualdad y en redes de acumulación de capital que posibilitan la supervivencia del sistema monopólico. Así, América y cada uno de los países que la componen, se entenderán como parte de un sistema planetario constituido por un centro, una periferia y una semiperiferia, en donde las particularidades son importantes, pero no determinantes. Esto implica reformular la relación entre economía y política, la articulación entre lo nacional y lo internacional, los criterios de periodización, las relaciones de dominación.

Por ejemplo, tomemos en cuenta algunos criterios de periodización para, desde la historia comparada boliviana-chilena, ampliar la mirada hacia la globalización. La relación entre Bolivia y Chile en el sistemamundo es la historia de una relación de 500 años que se inicia con la conquista española, continúa durante la Colonia, en el proceso independentista, se bifurca a consecuencia de una guerra y queda atrapada por el centro en la configuración del mundo de la contemporaneidad.

Hoy es corriente señalar que nuestros países tienen un lugar común en la historia por similitud de lengua, religión y cultura. Ahora, aunque 
es un importante dato, no es determinante. Lo que determina la comunidad de intereses históricos es la pertenencia al sistema universal inaugurado en el siglo XVI. Recordemos que, cuando llegaron los españoles, el oro y la plata comenzaban a mermar en Europa; en palabras de Braudel, "la América viene a reemplazar en el Mediterráneo a las fuentes de abastecimiento de oro africano y a las minas alemanas de plata, menos productivas"; ${ }^{4}$ agréguese a esa necesidad europea el inicio de la acumulación originaria y se tendrá la explicación de la devastación de Potosí y el sufrimiento de Marga Marga. Pero esa riqueza ni siquiera sirvió para asegurar a España una vía hegemónica en el sistema-mundo, que emergía porque, por su carácter de capitalismo intermediario, fue desplazada por una Holanda favorecida por la Paz de Wetsfalia (1648), ocasión para la reconfiguración del mapa europeo y para su hegemonía mundial, con el consiguiente desarrollo de la piratería, la esclavitud y la creciente inversión del capital holandés en la economía inglesa. Tendencia que cambió en el siglo XVII porque, siguiendo a numerosos autores que señalan que el siglo XVII fue un siglo complejo, de abierta crisis, ${ }^{43}$ podría concluirse que dicha crisis preparó el camino para una nueva hegemonía, la inglesa, con el consiguiente impacto sobre el mundo colonial, asolado ahora por el contrabando, el corso y una guerra interminable demandante de riqueza.

La siguiente hegemonía mundial, la de Inglaterra, también fue compleja. Doblegada Holanda y demolidos los sueños napoleónicos, después de Trafalgar (1805), la economía insular británica encontró nuevos mercados en ultramar y, en medio de infinitas guerras, un tercio de las exportaciones mundiales fueron a parar al nuevo centro hegemónico, un centro que se industrializaba y convertía en el "taller del mundo". Mientras tanto, en medio de las guerras coloniales descollaban las de América, configurándose 24 naciones que, balcanizadas, reclamaron un lugar en la nueva división del trabajo, asignándoseles el papel de países primario-

${ }^{42}$ Fernand Braudel, El Mediterráneo y el mundo Mediterráneo en la época de Felipe II, 1953 , México, FCE, p. 403.

${ }^{43}$ Para un información pormenorizada, Immanuel Wallerstein, El mercantilismo y la consolidación de la economía-mundo europea 1600-1750, 2000, México, Siglo XXI (especialmente "Introducción: ¿Hubo una crisis en el siglo XVII?”, p. 5 ss.) 
exportadores, situación acompañada desde mediados del siglo XIX por la transición de las viejas aristocracias a oligarquías, configurándose un nuevo tipo y forma de Estado (excluyente) con una nueva estructura social, un nuevo orden político y modelo económico, situación que dio mayor visibilidad al rol de la potencia hegemónica y al peso de la economía-mundo.

En fin, volviendo al ejemplo chileno-boliviano, el conflicto que se establece entre ambos Estados-naciones se inscribe en la órbita de la economía-mundo. Dicho de otra manera, el diferendo que arrastró a Bolivia, Perú y Chile a la guerra de 1879, tuvo su prolegómeno en la crisis cíclica del capitalismo de 1874, momento de cambio histórico por la aparición del capital monopólico. Como lo ha demostrado el historiador L. Ortega, la crisis de la economía-mundo presionó sobre la economía nacional, originándose dos proyectos de salida, la reforma interna o la guerra. ${ }^{44}$ La decisión de la oligarquía, en trance de capturar el Estado, fue ésta, por lo que el excedente salitrero fue fundamental para la construcción del Estado excluyente. ${ }^{45}$ Entonces, la guerra para la oligarquía chilena significó golpear los Estados-nación fronterizos y reprimir internamente al subalterno, incorporado al campo de batalla por medio de medidas compulsivas (levas forzosas) y a continuación por medio de una exitosa operación ideológica por medio de los aparatos ideológicos de Estado. Luego, una vez consolidado el poder geopolítico e interno, la historiografía dominante y oficial convertiría la historia de un conflicto intraoligárquico en una gesta de todos los chilenos. Entonces, en el origen de las guerras regionales, no puede desconocerse la incidencia de la economía-mundo.

Por otra parte, siguiendo la propuesta de Hobsbawm, en el sentido, que la historia es universal o no lo es, nuestra América no puede dejar de analizarse como una unidad en el contexto de un sistema más complejo, caracterizado por una sucesión de ciclos, el primero de ellos conformado por España/Portugal en los siglos XV-XVI, ciclo ocupado por

${ }^{44}$ Luis Ortega, Chile en ruta al capitalismo. Cambio, euforia y depresión, 1850-1880, 2005, Santiago, DIBAM.

${ }^{45}$ Enrique Fernández, Estado y sociedad en Chile, 1891-1931, 2003, Santiago, LOM. 
Holanda en el siglo XVII, reemplazado por el de Inglaterra en el XIX y hegemonizado por los Estados Unidos en el XX. Ahora bien, en cada uno de estos siglos encontramos un centro hegemónico de acumulación donde se organiza el dominio a escala mundial a partir del desplazamiento a los espacios más rentables, para luego abandonarlos cuando comienzan a decaer las ganancias (como es el caso de las independencias africanas), de manera que, cuando se deprime la rentabilidad, el capital adopta la forma de capital financiero, recordemos que Ámsterdam se convirtió en el banquero de Europa, tal como después lo hizo Inglaterra, abandonando la revolución industrial.

\section{El último ciclo... ¿ad portas de un nuevo cambio?}

En fin, ¿será la integración crítica de autores y conceptos la vía para reposicionar en la historiografía una visión global del factor internacional? Tal vez en la confluencia del viejo Marx con Braudel en torno a la materialidad societal, la revisión de la invención de América, el impacto de la colonialidad y de la desacumulación, enmarcados en la teoría de una periferia/centro, sometida a un ajuste estructural permanente, sean el camino para ampliar la visión a través de una teoría-mundo que explique la tendencia global a la desestructuración de un sistema que desde el siglo XVI ha tenido diferentes hegemonías en su centro.

En ese sentido, la pesquisa indica, respecto al último ciclo, el de la hegemonía norteamericana, que éste comienza con una gran depresión (1873-1896), que se propagó al igual que los ciclos pasados, por medio de la guerra (la nueva guerra de los “treinta años", 1914-1945), logrando a continuación una enorme expansión en lo que se denomina "edad del oro" del capitalismo, para entrar en crisis, producto de la lucha por la hegemonía por parte de Japón y Alemania, lo que obligó a la recomposición de 1974 (transición al capital financiero), lo que más bien podría interpretarse, dada la frecuencia de la crisis, como la transición hacia un nuevo ciclo de lucha hegemónica, del cual podría emerger un nuevo centro. En este contexto, ya no tienen cabida 
PATRICIO QUIROGA

las invocaciones decimonónicas sobre la hermandad latinoamericana. Lengua e historia son ahora insumos para enfrentar, unidos en el contexto del sistema-mundo, el creciente colapso de la economía-mundo, con el fin de construir una sociedad mejor que, respetando las particularidades, se enmarque en un plano más amplio, el de la humanidad en su conjunto, sobre todo en momentos en que la evidencia parece indicar que enfrentamos un nuevo cambio histórico universal.

La complejidad de esta tendencia ha sido recientemente formulada por los argentinos Rapoport y Brenta:

¿Le tocará ahora a EE.UU. vivir una lenta decadencia como la que tuvo Gran Bretaña desde finales del siglo XIX hasta la segunda posguerra? ¿Podrá recuperarse como en el pasado gracias, en buena medida, a circunstancias excepcionales, como las guerras; o la posibilidad de descargar sus crisis sobre otros países; o al repentino derrumbe de sus rivales, como pasó con la ex URSS; o debido a un salto tecnológico basado en innovaciones que aún no se vislumbran? ${ }^{46}$

Esta discusión se proyecta hace ya algunos años; mientras tanto, la competitividad de la economía norteamericana sigue disminuyendo, acompañada ahora de la desvalorización del dólar. La fortaleza militar pareciera estrellarse en Irak y Afganistán; en tanto que comienza a experimentarse un reacomodo de carácter geopolítico, impensable hace algunos años, como es la proyección de China (ahora, desde febrero, 2011, segunda economía mundial). El declive que se avizora en el largo plazo también ha sido vislumbrado por distintos especialistas en el tiempo histórico, a partir de la crisis abierta en 2007. ${ }^{47}$

${ }^{46}$ Mario Rapoport y Noemí Brenta, Las grandes crisis del capitalismo contemporáneo, 2010, Buenos Aires, Capital Intelectual, p. 355.

${ }^{47}$ Para Eric Hobsbawm vivimos "la más grave crisis del capitalismo desde la década de 1930"; según Ignacio Ramonet estamos viviendo "la crisis del siglo"; para Immanuel Wallerstein, "el Capitalismo se acaba" y para Giovanni Arrigí vivimos en una situación de "caos". El primero advierte sobre cambios de gran trascendencia; el segundo, el derrumbe del ciclo financiero; el tercero anuncia el fin de la hegemonía norteamericana y el cuarto el traslado de ésta hacia China. En suma, la transición ya habría comenzado para, en un mediano plazo, materializarse (20/30 años). Ver E. Hobsbawm, ¿Qué opina Hobsbawn sobre 
Ahora bien, la transformación en ciernes, desde una perspectiva sudamericana, obliga a poner la mirada en el modelo de país que se quiere, para saltar sobre la sombra de los mercados autorregulados, responsables de los traumáticos cambios de las últimas décadas, lo que significa poner en interdicción la matriz de pensamiento neoliberal y redoblar los esfuerzos del rearme intelectual que se está experimentando.

la crisis?, en http//www.rebelion.org/noticia php?id=74732; I. Ramonet, La crisis del siglo, en http//www.rebelion.org/noticia.php?id =73489; I. Wallerstein, El capitalismo se acaba, en http://www.rebelion.org/noticia.php'=74554; G. Arrighi y B. J. Silver, Caos y orden en el sistema-mundo moderno, 2001, Madrid, Akal. 
